\title{
$ノ-1$
}

Jjpn. J. Hosp. Pharm.

$\left[\begin{array}{lll}21(5) & 404-408 & (1995)\end{array}\right]$

\section{A Case Study on Cyclosporine $A$ in a Patient with Acute Hepatitis}

\author{
Masayuki Kadoyama, Kenji Kihira, Katsushi Miyake, \\ Teruaki Kitaura, Yasuhiro Kimura, Minoru Yoshida \\ and HIROSHI FUKUCHI
}

Department of Pharmaceutical Services, Hiroshima University Hospital ${ }^{\dagger}$

$\left(\begin{array}{l}\text { Received December 1, 1994 } \\ \text { Accepted June 28, } 1995\end{array}\right)$

\begin{abstract}
The relationship between the pharmacokinetics of Cyclosporine $\mathrm{A}(\mathrm{CyA})$ and the hepatic function was studied in a 15-year-old woman with hepatitis. At the early stage of treatment, the values of glutamic oxaloacetic transaminase (GOT), glutamic pyruvic transaminase (GPT), and total serum bilirubin (t-Bil) were higher than the normal range, suggesting hepatic cell injury and impaired bile formation and/or duct. The blood concentration ratio of CyA metabolites (Met) to CyA was markedly decreased from 1.92 to 0.74 in accordance with the clinical improvement in liver function. In addition a significant positive correlation was demonstrated between the Met/CyA ratio and GOT $(r=0.621, \mathrm{p}<0.05)$, GPT $(r=0.678$, $\mathrm{p}<0.02)$ and $\mathrm{t}-\mathrm{Bil}(\mathrm{r}=0.824, \mathrm{p}<0.001)$, while no significant correlation were found in the concentration-to-dosage ratio of $\mathrm{CyA}$ and Met. These results suggest the Met/CyA ratio could be a useful indicator for evaluate the clinical response and/or hepatic function. We would like to report this as a typical case that presented on apparent correlation of Met/CyA with liver functions. These results also indicate that the Met level as well as the unchanged CyA level should be evaluated in the hepatitis patient.
\end{abstract}

Keywords - Cyclosporine A, acute hepatitis, liver function

\section{INTRODUCTION}

CyA has been used as an immunosuppressive agent to inhibit graft rejection in transplantation such as kidney, liver, lung, and pancreas, resulting in a substantial improvement of patient and graft survival ${ }^{1}$. CyA has been also used for self-immunosensitive diseases like acute hepatitis ${ }^{2)}$. However, CyA has serious nephrotoxicity, neurotoxicity, and hepatotoxicity as its adverse effect ${ }^{3,4}$. CyA is absorbed from intestine with the micelles that are formed by the bile, metabolized in the liver, and eliminated in the bile and urine ${ }^{5}$. Therefore pharmacokinetics of CyA is influenced by the functional status of the liver. It has been reported that the bioavailability was least in liver recipients with liver disease and high bilirubin levels ${ }^{5}$. Wallemacq found a negative correlation between CyA levels and bilirubin 
concentrations $^{6}$. Treger also reported a significant negative correlation between CyA levels and GOT, alkaline phosphatase, bilirubin and $\gamma$-glutamyltransferase concentrations ${ }^{7}$. Most of these reports, however, have been studied in liver recipients, few has reported for patients with hepatitis. In the previous report we investigated the pharmacokinetic behavior of $\mathrm{CyA}$ and its metabolites (Met) in the patients with renal transplantation, hepatitis, and primary biliary cirrhosis and found that liver function affects on the pharmacokinetic behaviors of CyA and the Met/CyA ratio statistically correlates with liver function such as GOT, GTP, and $\mathrm{t}-\mathrm{Bil}^{8)}$.

In this study, we present a typical case that the pharmacokinetics of CyA correlates with hepatic function in a patients with hepatitis.

\section{CASE REPORT}

A 15-year-old woman with the suspicious of acute hepatitis was admitted to the Department of Internal Medicine I, Hiroshima University Hospital, in November 1993. She participated in this study after giving the informed consent in accordance with institutional guidelines. On the first day after hospitalization, the laboratory value was $679 \mathrm{U} / 1,954 \mathrm{U} / 1$ and $19.2 \mathrm{mg} / \mathrm{dl}$ for GOT, GPT and t-Bil, respectively, indicating the decreased hepatic function and the impaired bile formation or duct. And there showed no evidence of ascites. The renal and hematological functions were in the normal range. None of hepatic virus antigen was positive. Finally, this patients was diagnosed as a subacute hepatitis after hepatic biopsy.

On the next day, patient received Glucagon-Insulin therapy to improve hepatic function and 50 mg of CyA (Sandimmun ${ }^{\mathrm{TM}}$ ) to inhibit hepatic cell injury. One month later, the dosage of CyA was decreased to alternative administrations of $50 \mathrm{mg}$ and $25 \mathrm{mg}$ due to the improvement in hepatic function. Eventually, the dosage of CyA decreased $25 \mathrm{mg}$ on the alternative day at the end of hospitalization. During this treatment, ranitidine $\left(Z_{a n t a c}{ }^{\mathrm{TM}}, 150 \mathrm{mg} /\right.$ day), soluble azulen (Marzulene $\mathrm{S}^{\mathrm{TM}}$, $2 \mathrm{~g} /$ day) and ursodeoxycholic acid (Urso ${ }^{\mathrm{TM}}, 300 \mathrm{mg} /$ day)) was concomitantly administered. After two month, she left the hospital. The clinical data was $21 \mathrm{U} / 1,31 \mathrm{U} / 1$ and $1.3 \mathrm{mg} / \mathrm{dl}$ for GOT, GPT and $\mathrm{t}$-Bil, respectively, showing favorable control of hepatic functions. In addition, reproduced hepatic cells were also shown by hepatic biopsy.

\section{METHODS}

All blood samples were obtained at trough level before oral CyA administration in the morning. The blood concentrations of $\mathrm{t}-\mathrm{CyA}$ and $\mathrm{CyA}$ were measured by Fluorescence Polarization Immunoassay (TDX system) using polyclonal or monoclonal antiserum, respectively ${ }^{9}$. The blood concentration of Met was obtained by subtracting CyA concentration from t-CyA concentration.

\section{CLINICAL DATA}

Clinical data of GOT, GPT, and t-Bil were obtained at the Clinical Laboratory Services of Hiroshima University Hospital with an automatic analyzer (Model 7250, Hitachi Co. Ltd., Tokyo Japan). 


\section{RESULTS AND DISCUSSION}

Present study demonstrated the correlation of the pharmacokinetic profiles of CyA and a liver function in a patient with acute hepatitis. Table 1 summarized the time profiles of concentration/dose ratio ( $\mathrm{C} / \mathrm{D}$ ratio) of $\mathrm{t}-\mathrm{CyA}, \mathrm{CyA}$ and Met. The time course profiles of Met/CyA ratio and liver functions were illustrated in Fig. 1. The clinical value in an earlier stage were higher than normal range, suggesting a hepatic cell injury and the impaired bile formation or duct. These clinical data may also indicate the decreased bioavailability, metabolism and bile excretion since CyA is absorbed from intestine as a micelle with bile salts, metabolized in the liver and excreted in the bile ${ }^{5)}$. In the previous report ${ }^{8)}$, we have found higher $\mathrm{C} / \mathrm{D}$ ratios of $\mathrm{t}-\mathrm{CyA}, \mathrm{CyA}$ and Met compared with those in renal recipients whose hepatic function was in the normal range. In addition, the Met/CyA ratios were higher in the following order of primary biliary cirrhosis, hepatitis and renal transplantation. Furthermore these ratios were significantly correlated with GOT, GPT and t-Bil. Based on these finding, we have provided following assumption that the patients with hepatitis excreted bile salts to keep a minimum requirement of normal $\mathrm{CyA}$ absorption and maintained substantial metabolic ability on CyA even in that state, therefore the observed higher $\mathrm{C} / \mathrm{D}$ ratios of $\mathrm{CyA}$ and Met, and Met/CyA ratio might be attributable to the decreased excretion of CyA and Met in the bile and increased efflux of those in the systemic circulation. Especially, these mechanism seemed to be effective in Met.

In the present study, the $\mathrm{C} / \mathrm{D}$ ratios of $\mathrm{CyA}$ and Met were found in high level. Furthermore, the Met/CyA ratio in an earlier stage also showed higher than that obtained in renal recipients (1.18 $\pm 0.3)^{8}$. The Met/CyA ratio was markedly decreased from 1.92 to 0.74 in accordance with the clinical improvement of a liver function as shown in Fig. 1. The final value well corresponded with the value obtained from the patient with renal transplantation ${ }^{8}$. It has been reported that significant negative correlation between $\mathrm{CyA}$ and a hepatic function ${ }^{6,7)}$. Therefore, the relationship between the $\mathrm{C} / \mathrm{D}$

Table 1. Whole Blood Concentration Ratio of Cyclosporine A to Dose

\begin{tabular}{|c|c|c|c|c|c|c|c|c|}
\hline \multirow{2}{*}{ Days } & \multicolumn{2}{|c|}{ DOSE } & \multicolumn{3}{|c|}{ Blood Concentration (ng/ml) } & \multicolumn{3}{|c|}{ C/D Ratio* } \\
\hline & (mg) & $(\mathrm{mg} / \mathrm{kg})$ & $\mathrm{t}-\mathrm{CyA}$ & CyA & Met & $\mathrm{t}-\mathrm{CyA}$ & $\mathrm{CyA}$ & Met \\
\hline 1 & 50 & 1.1 & 227.2 & 77.7 & 149.5 & 209.0 & 71.5 & 137.5 \\
\hline 2 & 100 & 2.2 & 371.3 & 151.9 & 219.4 & 170.8 & 69.9 & 100.9 \\
\hline 4 & 75 & 1.6 & 384.9 & 138.9 & 246.0 & 236.1 & 85.2 & 150.9 \\
\hline 5 & 75 & 1.6 & 453.6 & 175.6 & 278.0 & 278.2 & 107.7 & 170.5 \\
\hline 8 & 50 & 1.1 & 458.6 & 203.6 & 255.0 & 421.9 & 187.3 & 234.6 \\
\hline 10 & 50 & 1.1 & 352.7 & 151.8 & 200.9 & 324.5 & 139.7 & 184.8 \\
\hline 12 & 50 & 1.1 & 312.4 & 113.2 & 199.2 & 287.4 & 104.1 & 183.3 \\
\hline 15 & 50 & 1.1 & 319.5 & 125.0 & 194.5 & 293.9 & 115.0 & 178.9 \\
\hline 17 & 50 & 1.1 & 244.5 & 117.0 & 127.5 & 224.9 & 107.6 & 117.3 \\
\hline 19 & 50 & 1.1 & 275.4 & 112.4 & 163.0 & 253.4 & 103.4 & 150.0 \\
\hline 22 & 50 & 1.1 & 312.3 & 127.1 & 185.2 & 287.3 & 116.9 & 170.4 \\
\hline 29 & 50 & 1.1 & 344.1 & 187.8 & 156.3 & 316.6 & 172.8 & 143.8 \\
\hline 36 & 50 & 1.1 & 213.7 & 107.8 & 105.9 & 196.6 & 99.2 & 97.4 \\
\hline 54 & 25 & 0.5 & 51.1 & 29.3 & 21.8 & 98.1 & 56.3 & 41.9 \\
\hline
\end{tabular}

${ }^{*} \mathrm{C}$ : whole blood concentration (in $\mathrm{ng} / \mathrm{ml}$ ), D: dose based on body weight (in $\mathrm{mg} / \mathrm{kg} /$ day). 


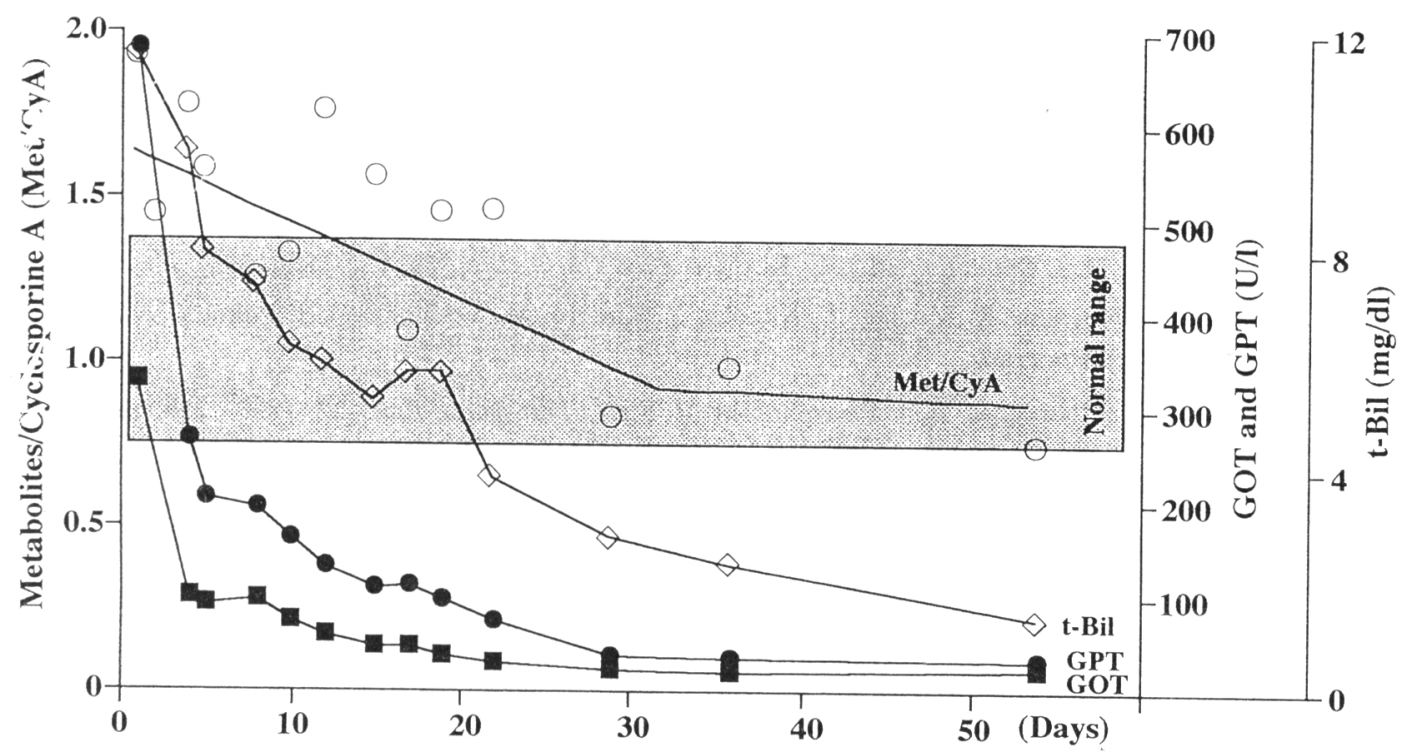

Fig. 1. Profile of the ratio of metabolites / cyclosporine A (Met/CyA) in a patient with acute hepatitis. The symbols, $\bigcirc$, $\bullet$, and $\diamond$, mean Met/CyA, glutamic oxaloacetic transaminase (GOT), glutamic pyruvic transaminase (GPT), and total serum bilirubin ( $\mathrm{t}$-Bil), respectively. The shadowed area means the normal range $(1.18 \pm 0.3)$ of $\mathrm{Met} / \mathrm{CyA}$ obtained in the previous report ${ }^{8}$.

ratios and the Met/CyA ratio and liver functions were investigated by using a linear regression analysis. Although none of the $\mathrm{C} / \mathrm{D}$ ratio correlated with the hepatic function, there showed significant positive correlation between Met/CyA ratio and GOT ( $\mathrm{r}=0.621, \mathrm{p}<0.05)$, GPT $(\mathrm{r}=0.678, \mathrm{p}<0.02)$ and $\mathrm{t}$-Bil $(\mathrm{r}=0.824, \mathrm{p}<0.001)$.

These results clearly indicate the importance of the Met/CyA ratio in a patient with hepatitis. Especially, the enhanced Met level might be affected rather than CyA by the decreased hepatic function.

In conclusion, the Met level should be evaluated as well as unchanged CyA level in a patient with hepatitis. In addition, the Met/CyA ratio could be a useful indicator to evaluate the clinical response and/or hepatic function.

\section{ACKNOWLEDGMENT}

We wish to thank the Doctors of the Department of Internal Medicine I, Hiroshima University Hospital (Professor and Director, Goro Kajiyama, M.D., Ph.D.), Hiroshima University, for giving us an opportunity for TDM of CyA, and also the Clinical Laboratory Services, Hiroshima University Hospital (Professor and Director, Masayuki Kambe, M.D., Ph.D.) for offering us the clinical data.

\section{REFERENCES}

1) A. Lindberg, B. Odlind, G. Tufveson, B. Lindström and J. Gabrielsson, Transplant. Proc., 18 (suppl. 5), 446-453 (1986). 
2) B. Graffenried, Prog. Allergy, 38, 432-435 (1986).

3) A. Davenport, E. J. Will, A. M. Davison and J. W. Ironside, Lancet II, 333 (1988).

4) K. Leunissen, G. Baumann, R. Bosman and J. P. Van Hoof, J. P. Lancet II, 1398 (1986).

5) A. Lindberg, Ther. Drug Monit., 13, 465-477 (1991).

6) P. E. Wallemacq, M. Lesne and J. B. Otte, Clin. Transplant, 1, 132-137 (1987).

7) S. G. Carruthers, D. J. Freeman and J. C. Koegler, Clin. Chem. Acta, 29, 180-183 (1983).

8) K. Kihira, M. Kadoyama, K. Miyake, T. Kitaura, Y. Kimura, M. Yoshida and H. Fukuchi, Hiroshima J. Med. Sci., 43, 175-178 (1994).

9) N. Sridhar, T. J. Sdhoroeder, A. J. Pesce and M. R. First, Transplant. Proc., 22, 1257-1259 (1990). 